\title{
Partial resection of persistent left superior vena cava for a T4 lung cancer
}

\author{
Erdal Okur, MD, Cagatay Tezel, MD, Volkan Baysungur, MD, and Semih Halezeroğlu, MD, Istanbul, Turkey
}

Although persistent left superior vena cava (PLSVC) is one of the most common congenital variations in the thoracic venous system, its resection for lung cancer has not been reported previously. We report partial resection of PLSVC together with a centrally located carcinoma in the left lung.

\section{CLINICAL SUMMARY}

A 55-year-old man with a new onset of hemoptysis was admitted to the Sureyyapasa Chest Diseases and Thoracic Surgery Teaching and Research Hospital (Istanbul, Turkey). He had no history of previous disorders. Physical examination and routine laboratory tests showed normal results. A mass lesion in the left hilum was observed on chest $\mathrm{x}$-ray. Fiberoptic bronchoscopy displayed an obstruction of the left upper lobe bronchus with a tumoral lesion. Pathology results of the biopsy showed squamous cell carcinoma. There was a $3-\mathrm{cm}$ tumoral mass located in the left hilum of the lung adjacent to the pulmonary artery and vein on computed tomography (CT). A circular-shaped $(10 \mathrm{~mm}$ in its biggest axes) paraaortic lesion seen on CT was evaluated as a benign lymph node (Figure 1).

A left thoracotomy was performed for a clinical T4NOM0 lung cancer. A centrally located tumor invading the pericardium was observed on exploration. An abnormal vessel that descended from the apex of the thorax downward along the mediastinal surface, lateral to the aortic arch and anterior to the pulmonary artery, and that entered the pericardium was observed (Figure 2, A). The left subclavian venous catheter that was inserted before thoracotomy was palpated in the lumen of the vein. This abnormal vein was invaded by the tumor where it entered the pericardium. This vascular structure was seen as draining into the coronary sinus when the pericardium was opened to ascertain the resectability of the tumor. All of these findings revealed that this vein was a PLSVC.

After the pulmonary artery was divided and the left main bronchus was cut, a clamp was placed on the left atrium and

\footnotetext{
From the Department of Thoracic Surgery, Sureyyapasa Chest Disease and Thoracic Surgery Education and Research Hospital, Istanbul, Turkey.

Received for publication Oct 18, 2007; accepted for publication Nov 29, 2007.

Address for reprints: Semih Halezeroğlu, MD, Sureyyapasa Chest Disease and Thoracic Surgery, Educational and Research Hospital, Maltepe 34758 Istanbul, Turkey (E-mail: semihh@atlas.net.tr).

J Thorac Cardiovasc Surg 2008;136:1080-1

$0022-5223 / \$ 34.00$

Copyright (c) 2008 by The American Association for Thoracic Surgery doi: $10.1016 /$ j.jtcvs.2007.11.070
}

it was resected and sutured. Another clamp was applied to the lateral part of the PLSCV where it was invaded by the tumor. The invaded part was cut with a macroscopically tumor-free margin and sutured with 4-0 Prolene. After systematic mediastinal lymph node sampling, the chest was closed in the usual way.

The postoperative period was uneventful. Definitive pathology revealed R0 resection with pathologic stage T4N0 resulting from both left atrium and vena cava invasion. Echocardiography was performed to investigate accompanying cardiac problems and revealed no abnormality. Venography was performed to demonstrate the postoperative grade of the PLSVC narrowing and the drainage pathway of the anomaly (Figure 2, B).

\section{DISCUSSION}

PLSVC is one of the most common congenital variations in the thoracic venous system with an incidence of $0.3 \%$ to $0.5 \%$ in the healthy population and $4.3 \%$ in those with congenital heart disease. ${ }^{1}$ During normal embryogenesis, failure of obliteration of the left cardinal vein results in PLSVC. ${ }^{2}$

In general, patients with PLSVC have a normal right superior vena cava (SVC) and no symptoms. However, Yamada and colleagues ${ }^{3}$ reported a patient with a left SVC but no right SVC. This condition usually requires no treatment and has no adverse effect on hemodynamic status when there is no associated cardiac abnormality. The importance of PLSVC is the greater prevalence of associated congenital cardiovascular defects and higher incidence of rhythm disorders. The most common associated lesion is an intra-atrial septal defect. ${ }^{4}$ For this reason, exclusion of concomitant heart disease is an important situation before undergoing a major operation.

The condition is usually diagnosed after the placement of a central venous catheter; catheter placement is generally difficult because advancement of the catheter is impeded, as occurred in our case. Manipulation of the venous lead through this unusual venous route may be associated with complications. Accurate diagnosis can be achieved by echocardiography in conjunction with Doppler or contrast ultrasonography with an appearance of a dilated, echo-free space posterior in the atrioventricular groove between the left atrium and the ventricle. ${ }^{4}$

In the present case, we misinterpreted PLSVC as a lymphadenopathy on horizontal CT slices in the preoperative period. Because of the rarity of the situation, a similar misdiagnosis was reported by Wong and Goldstraw. ${ }^{5}$ 

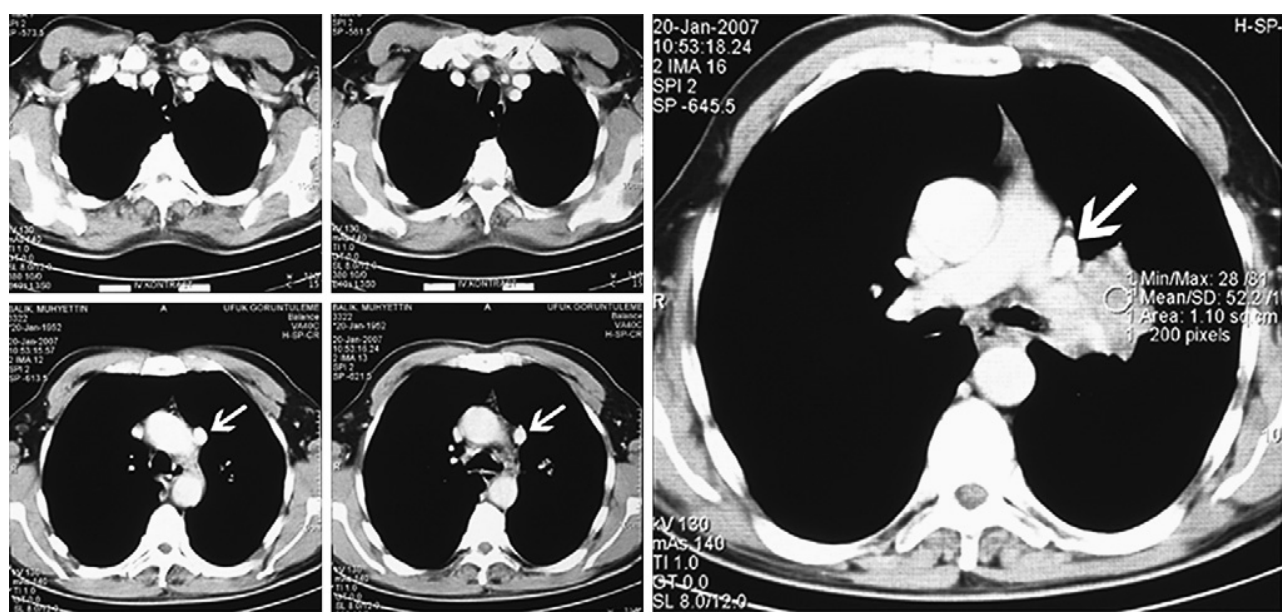

FIGURE 1. CT of the chest showing the PLSVC descending lateral to the aortic arch and anterior to the left hilum with central tumor.
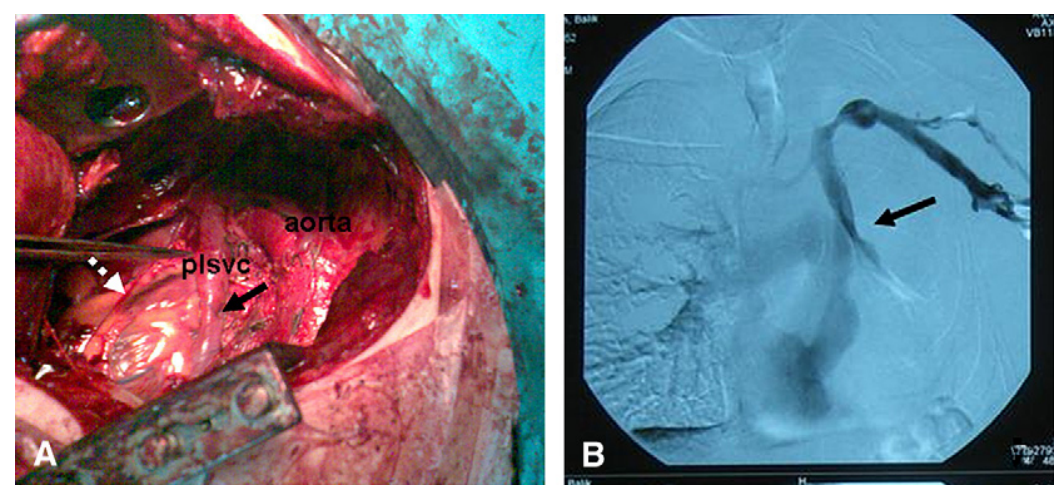

FIGURE 2. A, PLSVC in the thoracic cavity after left pneumonectomy: partial resected PLSVC (black arrow) and opened pericardium (white arrow). B, Postoperative venography showing PLSVC and narrowed segment (arrow) after partial resection. PLSVC, Persistent left superior vena cava.

Resection of the right SVC for lung cancer in a setting of complete resection has been performed for years. This current case shows that partial resection of PLSVC in the case of its invasion by lung cancer is also possible.

\section{References}

1. Pahwa R, Kumar A. Persistent left superior vena cava: an intensivist's experience and review of the literature. South Med J. 1996;5:528-9.

2. Lucas RV Jr, Krabill KA. Abnormal systemic venous connections. In: Emmanouilides GC, Riemenschneider TA, Allen HD, eds. Moss and Adams
Heart Disease in Infants, Children and Adolescents: Including the Fetus and Young Adult. 5th ed. Baltimore, MD: Williams and Wilkins; 1995: 874-8.

3. Yamada M, Koshika M, Goto S, Ito K. Lung cancer which accompanies anomalous venous connections, pulmonary and systemic-partial anomalous pulmonary venous connection and persistent left superior vena cava: report of 2 cases. Kyobu Geka. 2005;58:399-402.

4. Sarodia BD, Stoller JK. Persistent left superior vena cava: case report and literature review. Respir Care. 2000;4:411-6.

5. Wong PS, Goldstraw P. Left superior vena cava: a pitfall in computed tomographic diagnosis with surgical implications. Ann Thorac Surg. 1990;50: 656-7. 